\section{Corrected numbers for fish on Red List}

Kelly Swing gives inaccurate numbers for marine fish species on the International Union for Conservation of Nature (IUCN) Red List of Threatened Species. He also mistakenly conflates the scientific process of species assessment for the Red List with the separate political process of IUCN member voting (Nature 494, 314; 2013).

About one-quarter, or 4,337, of some 17,000 species of marine fish are on the IUCN Red List (not fewer than 100 species out of 25,000 , as Swing writes). Of those, 416 species have been placed in a threatened category (Critically Endangered, Endangered or Vulnerable) and 1,180 species were classed as Data Deficient.

The IUCN Tuna and Billfish Specialist Group has assessed all 10 species of billfish and 51 species of tuna and mackerel through a series of regional workshops, unhindered by the "IUCN's worldwide voting procedures". Seven species meet the IUCN threshold for a threatened category

(B. B. Collette et al. Science 333, 291-292; 2011). The sale of billfish has since been banned in the continental United States.

The IUCN Marine Biodiversity Unit's Global Marine Species Assessment programme is now evaluating all remaining marine fish, and aims to finish within 5 years (http://sci.odu.edu/gmsa). Bruce B. Collette National Marine Fisheries Service, Washington DC, USA. collettb@si.edu

Beth Polidoro Arizona State University, Phoenix, USA. Kent Carpenter Old Dominion University, Norfolk, Virginia, USA.

\section{Regulating stem-cell therapies worldwide}

Japan's drive to regulate experimental stem-cell treatments is a welcome step (Nature 494, 5; 2013). However, it could be hard to define universally applicable criteria that ensure the safety and effectiveness of such treatments worldwide.

There is a risk that the social and economic circumstances of patients and researchers might blur or compromise crucial criteria, such as evidence-based support (including adequate preclinical and clinical testing), ethical review and no-fee experimental treatment.

Stem-cell therapies are all too often unsupported by scientific evidence, but many patients are prepared to accept the risks. And nations with inadequate health-care resources may expect patients to pay for experimental treatments.

Proliferation of experimental stem-cell therapies may even be indirectly encouraged in countries such as China, where ultra-light regulation through official notification (see www. moh.gov.cn) has uncertain regulatory value. Margaret Sleeboom-Faulkner University of Sussex, Brighton, UK. m.sleeboom-faulkner@sussex.ac.uk

\section{Order health systems in developing world}

Governments and policy-makers are aiming to improve health markets in developing countries as they take up the challenge of last year's United Nations resolution to move towards universal health coverage (see go.nature.com/acsmss). We caution that they must do more than simply legislate their way to a more orderly health system.

We have highlighted the risks associated with unregulated health-care services and products in developing countries (Nature 487, 163-165; 2012). We now wish to draw governments' attention to improvements proposed at a conference on securing international agreements on future health markets.

A small group of health policymakers, entrepreneurs, academics and funders met in Bellagio, Italy, at the end of last year. Among their recommendations were that countries should establish systems for collecting better basic health-market data for incorporation into local policy and management processes, and that they should organize funds to promote sound regulatory practice (see go.nature.com/ npsdvg).

The group called for a major effort by all market players to test innovative regulatory approaches and business models to improve access to safe and effective health services in the developing world. David H. Peters Johns Hopkins Bloomberg School of Public Health, Baltimore, Maryland, USA.

dpeters@jhsph.edu

Gerald Bloom University of Sussex, Brighton, UK.

\section{Modelling genetics within ecosystems}

Safeguarding genetic diversity is one of the Convention on Biological Diversity's main targets, because genetics underpins ecosystems. General models of whole ecosystems (D. Purves et al. Nature 493, 295-297; 2013) therefore need to incorporate genetic data if they are to represent natural systems and guide conservation policy.

Yet it is important to understand that species diversity and genetic diversity do not always correlate; that the interplay between phylodiversity and functional diversity can be highly complex and regulated by interactions between cornerstone species; and that ecosystem resilience is tied to evolutionary history and genetic diversity. An ecosystem's full genetic potential, as represented by ancient lineages and maximally diverse taxa and key species, must be realized.

Niall McCann, Pablo Orozco ter Wengel, David Stanton Cardiff University, Cardiff, UK. mccannnp@cardiff.ac.uk
Drew Purves et al. reply: It could be useful to incorporate genetics into general ecosystem models (GEMs), along with complexities such as stoichiometry or longrange migrations. Genetically based GEMs could interface with the increasing amounts of genetic data available to capture the effects of individual-scale adaptation, although this can be approximated without explicit genetics (for example, traits mutate in the Madingley model we describe in our Comment). However, such complexities bring greater computational demands and increased model freedom, which might lead to the model producing almost any output unless properly constrained with data.

\section{Evaluate gender equality in journals}

The European Association of Science Editors established a gender policy committee last year to develop a set of standards for adoption by scientific journals. As co-chairs of the committee, our first step is to invite science editors to contribute to a survey of genderequality policies in their journals (see go.nature.com/wor7ks; survey closes on 10 April).

In this survey, we ask editors for their views on considering sex and gender in experimental design and data analysis, and on presenting data that are broken down by sex. Information is also requested on gender balance and its promotion among editorial staff, editorial boards and peer reviewers.

Our hope is that all journals will eventually follow Nature's example in promoting gender equality in science (see www. nature.com/women). Shirin Heidari Journal of the International AIDS Society, Geneva, Switzerland. shirin.heidari@iasociety.org Tom Babor University of Connecticut School of Medicine, Farmington, Connecticut, USA. 